\title{
Sinus node structural changes in patients with long-standing chronic atrial fibrillation
}

\author{
Aquilino Hurlé, MD, PhD, FETCS, ${ }^{a}$ Vicente Climent, $\mathrm{MD}, \mathrm{PhD}^{\mathrm{b}}$ and Damian Sánchez-Quintana, MD, PhD, ${ }^{\mathrm{b}}$ \\ Alicante and Badajoz, Spain
}

$\mathrm{T}$ he normal structural disposition of the sinus node $(\mathrm{SN})$ is well documented in the literature. ${ }^{1}$ The histologic changes taking place within the atrial wall of patients with atrial fibrillation (AF) have also been described in the past. ${ }^{2}$ However, how SN histology might be affected by long-term $\mathrm{AF}$ is an issue that, to our knowledge, has not been previously addressed. The purpose of the present study is describing the $\mathrm{SN}$ microscopic features of patients with long-term permanent AF, which could be of relevance for the surgical treatment of this arrhythmia.

\section{Methods}

Sixteen patients (10 female and 6 male patients; mean age, $66 \pm$ 9 years) undergoing operations for rheumatic heart valve disease who were in chronic AF beyond surgical treatment (ongoing AF for more than 10 years, a left atrial transverse diameter greater than $60 \mathrm{~mm}$, as measured by means of transthoracic echocardiography, or both) were included in this study. Informed consent was obtained from all participants, and the study was approved by the local ethics committee. In all instances, a 4-mm transmural punch biopsy specimen was obtained from the most anterior part of the junction between the superior vena cava and the right atrium. Biopsy specimens were fixed immediately in $10 \%$ formaldehyde. They were then dehydrated and embedded in paraffin, cut into 7 - $\mu \mathrm{m}$-thick slides, and stained with Masson or Jones trichrome for histologic analysis.

Digital images $(512 \times 512$ pixels $)$ were taken from these histologic slides. Twenty measurements of $\mathrm{P}$ cell (impulse-producing cells) and SN working myocardial cell diameters (in micrometers) were randomly made on these digitalized images from each tissue block by using a linear measurement software program (SigmaScan Pro 4.0; Jandel Scientific, San Rafael, Calif). For each measurement, the widest cell cross-sectional diameter visible in the image was selected. These measurements were then averaged. The cell/ connective tissue ratio in the specimens was estimated with the aid of a grid of vertical and horizontal lines, providing 121 intersec-

\footnotetext{
From the Department of Cardiac Surgery, ${ }^{\mathrm{a}}$ Hospital General Universitario de Alicante, Alicante, Spain, and the Department of Human Anatomy, School of Medicine, University of Extremadura, Badajoz, Spain.

Received for publication Jan 25, 2006; accepted for publication Jan 30, 2006.

Address for reprints: Aquilino Hurlé, MD, Servicio de Cirugía Cardiaca, Hospital General Universitario de Alicante, C/ Pintor Baeza s/n, 03010 Alicante, Spain (E-mail: hurle_aqu@gva.es).

J Thorac Cardiovasc Surg 2006;131:1394-5

0022-5223/\$32.00

Copyright $\odot 2006$ by The American Association for Thoracic Surgery doi:10.1016/j.jtcvs.2006.01.031
}

tions of points. The total number of points was defined as $100 \%$, and the points overlying connective tissue were expressed as a percentage of the entire tissue within the limits of the grid. Blood vessels and perivascular interstitial tissue were excluded from the connective tissue quantification.

Five SN biopsy specimens obtained from the autopsies of 5 subjects ( 2 female and 3 male subjects; mean age, $52 \pm 20$ years) who were in sinus rhythm and died from noncardiac causes were fixed and processed in the same manner as the study biopsy specimens and served as control specimens.

\section{Results}

Five biopsy specimens of patients in AF showed fibrosis of the SN with total absence of myocardial cells as the only finding. P cells were absent in 6 further specimens. A significant increase in the proportion of connective tissue matrix could be demonstrated in the remaining $5 \mathrm{AF}$ specimens when compared with the control specimens $(34.5 \% \pm 4.0 \%$ for the study group vs $46.5 \% \pm 8.5 \%$ for the control group, $P<.05)$.

The diameter of $\mathrm{SN}$ cells, when present, was significantly increased in specimens from patients in AF when compared with control specimens. Thus $P$ cells averaged $7 \pm 2 \mu \mathrm{m}$ in diameter in the control group versus $11 \pm 4 \mu \mathrm{m}$ in the $\mathrm{AF}$ group $(P<.05)$, and working myocytes averaged $15 \pm 2 \mu \mathrm{m}$ in the control group versus $24 \pm 5 \mu \mathrm{m}$ in the $\mathrm{AF}$ group $(P<.05)$.

All these findings are shown in Figure 1.

\section{Discussion}

In recent years, great attention has been paid to the surgical treatment of AF by means of linear atrial ablation techniques. Different energy sources, such as radiofrequency, microwaves, cryoenergy, and others, have proved to be equally effective for

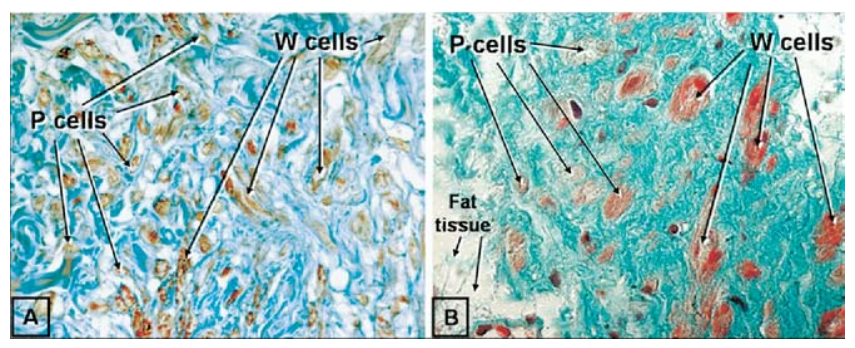

Figure 1. Sinus node. Trichrome stain $(190 \times)$ : A, control specimen; B, atrial fibrillation specimen. Note more abundant connective tissue and fewer and larger myocardial cells in the atrial fibrillation specimen when compared with the control specimen. $\boldsymbol{P}$ cells, impulse-producing cells; $\boldsymbol{W}$ cells, myocardial working cells. 
atrial ablation purposes. ${ }^{3}$ However, it is a known fact that patients with long-standing AF, giant atria, or both have a much smaller chance to revert back to sinus rhythm after these ablation procedures. $^{4}$

Our findings, herein reported, might provide an explanation to understand this fact. As we have described, the morphologic consequences of chronic AF on the normal SN can be synthesized in 3 main features: (1) progressive tissue fibrosis, (2) progressive myocardial cell loss (including P cells), and (3) myocardial cell degeneration (including $\mathrm{P}$ cells). These SN morphologic abnormalities must inevitably lead to an impairment of its function. Thus normal sinus rhythm is less likely to be restored in patients with long-standing $\mathrm{AF}$, regardless of the atrial lesion pattern used to interrupt re-entry or the energy source used to create these lesions because their $\mathrm{SN}$ is morphologically and functionally abnormal. Conversely, surgical treatment of AF during its early stages, with minimal SN damage, is more likely to be successful.

\section{References}

1. James TA. The sinus node. Am J Cardiol. 1977;40:967-86.

2. Davies MJ, Pomerance A. Pathology of atrial fibrillation in man. $\mathrm{Br}$ Heart J. 1972;34:520-5.

3. Khargi K, Hutten BA, Lemke B, Deneke T. Surgical treatment of atrial fibrillation; a systematic review. Eur J Cardiothorac Surg. 2005;27: 258-65.

4. Chen MC, Chang JP, Chang HW, Chen CJ, Yang CH, Chen YH, et al. Clinical determinants of sinus conversion by radiofrequency maze procedure for persistent atrial fibrillation in patients undergoing concomitant mitral valvular surgery. Am J Cardiol. 2005;96:1553-7.

\title{
Rapidly progressive coronary ostial stenosis after aortic valve replacement in relapsing polychondritis
}

\author{
R. Karthik Vaidyanathan, MS, ${ }^{a}$ Jagannath Raghavendrarao Byalal, DNB (CTS), ${ }^{\text {a }}$ \\ Thiagarajamurthy Sundaramoorthi, FRCS (CTS), ${ }^{a}$ N. Madhu Sankar, DNB (CTS), PhD, a Joy M. Thomas, DM (card), \\ N. Alagu Meenakshi, BS (PA), ${ }^{\text {b }}$ and Kotturathu Mammen Cherian, FRACS, ${ }^{a}$ Chennai, India
}

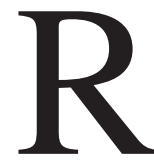

elapsing polychondritis is a rare multisystem disease characterized by inflammation of cartilage and other proteoglycan-rich structures, such as the eye, ear, heart, and blood vessels. ${ }^{1}$ Cardiovascular manifestations of this disease are rare, but they are the second most common cause of death in these patients. ${ }^{2}$ We report a case of relapsing polychondritis in which the patient underwent aortic valve replacement and had acute myocardial infarction caused by coronary ostial stenosis 6 months after the operation.

\section{Clinical Summary}

A 26-year-old woman presented with New York Heart Association class III dyspnea of 6 months' duration. She denied any anginal symptoms. Two years earlier, she was given a diagnosis of relaps-

From the Departments of Cardiac Surgery ${ }^{\mathrm{a}}$ and Cardiology, ${ }^{\mathrm{b}}$ Frontier Lifeline, International Centre for Cardiovascular and Thoracic diseases, Chennai, India.

Received for publication Jan 13, 2006; accepted for publication Jan 24, 2006.

Address for reprints: R. Karthik Vaidyanathan, MS, International Centre for Cardiovascular and Thoracic diseases, R 30 C Ambattur Industrial Estate Rd, Mogappair, Chennai-600101, India (E-mail: rkvdoc@ rediffmail.com).

J Thorac Cardiovasc Surg 2006;131:1395-6

$0022-5223 / \$ 32.00$

Copyright $\odot 2006$ by The American Association for Thoracic Surgery doi:10.1016/j.jtcvs.2006.01.032 ing polychondritis that had manifested as inflammation of the ear and depression of the nasal bridge. She had taken $20 \mathrm{mg} / \mathrm{d}$ oral prednisolone for a year and discontinued treatment because of relief of symptoms. She had clinical features suggestive of severe aortic regurgitation. Transthoracic echocardiography confirmed the presence of severe aortic regurgitation. Ejection fraction was $61 \%$. Erythrocyte sedimentation rate was $23 \mathrm{~mm} / 45 \mathrm{~mm}$. In view of her symptoms and severity of regurgitation, we decided to replace her aortic valve. Coronary angiography was not done because of her age, lack of anginal symptoms, and lack of electrocardiographic changes. Through a median sternotomy, cardiopulmonary bypass was instituted with cannulas in the ascending aorta and right atrium. Transverse aortotomy was performed, and cardioplegia was administered through the coronary ostia. The ascending aorta was thickened, and both coronary ostia appeared smaller than normal. The aortic valve was excised and replaced with a 23-mm Omni Carbon valve. Postoperative recovery was uneventful, and she was discharged home on the seventh postoperative day. Histology of the aortic valve revealed evidence of acute on chronic inflammation. Her New York Heart Association functional status improved to class I. She had recurrent inflammation of auricular cartilage 2 months after surgical intervention, and in consultation with the rheumatologist, she was restarted on $20 \mathrm{mg} / \mathrm{d}$ oral prednisone. She remained asymptomatic for 6 months and presented one day with acute-onset chest pain. Electrocardiography revealed acute anterior and lateral wall myocardial infarction. Coronary angiography revealed $75 \%$ and $90 \%$ ostial stenosis of the right and left coronary arteries, respectively. Immediate coronary artery bypass grafting was planned, but she sustained a fatal cardiac arrest while awaiting surgical intervention. 